\title{
Fotografia - Uma perspectiva ontológica em foco
}

Joel Staviski ${ }^{53}$

RESUMO: O intento deste artigo é resgatar os princípios fundamentais de uma visão ontológica e fenomenológica da Fotografia, como medida de interposição a banalização mediática. Desde a filosofia clássica tem-se procurado a essência da imagem como representação da realidade e com Vilém Flusser criou-se uma nova perspectiva sobre a possibilidade de uma filosofia aprofundada desta mídia, como um todo complexo entre homem-maquina-representação. Tal perspectiva expande-se ante a visão de Roland Barthes, em que o "ser em si" é ampliado e aplicado a esta arte, torna-se um contraponto necessário a esta fundamentação onto-fenomênica.

Palavras - Chave: Imagem; Fotografia; Representação; Flusser; Bar.

\section{Photography: an ontological perspective in focus}

\begin{abstract}
The purpose of this article is to rescue the fundamental principles of the ontological and phenomenological view of photography as an interposition measure to the media trivialization. Since classical philosophy the essence of the image has been sought as a representation of reality and Flusser created a new perspective on the possibility of an in-depth philosophy of this media as a whole complex of manmachine-representation. This perspective expands with Roland Barthes' vision, in which "being itself" is expanded and applied to this art, it is a necessary counterpoint to this onto-phenomenological grounds.
\end{abstract}

Key Words: Picture, Photography, Representation, Flusser, Barthes.

Submetido em: setembro de 2015.

Aprovado em: janeiro de 2016.

\section{INTRODUÇÃO}

Hodiernamente somos bombardeados por uma infinidade de conteúdos da mídia visual, que cada vez mais visam a mercantilização cultural de uma suposta arte, consequentemente sua banalização torna-se patente. A Fotografia tornou-se corriqueira e mesmo dir-se-ia parte integrante e indissolúvel da socialização, por meio das redes sociais e outros meios tecnológicos de compartilhamento e divulgação.

O presente artigo tem por objetivo levantar os fundamentos onto-fenomenicos da

\footnotetext{
${ }^{53}$ Fotógrafo Profissional. Formado em Filosofia pelo Centro Universitário Claretiano. E mail:gil-jr@uol.com.br
} 
Fotografia, os quais também são inerentes aos aspectos filosóficos da arte e da linguagem.

Para que tal proposta possa ser viabilizada, optou-se por elencar uma perspectiva dialética em uma revisão bibliográfica da obra "Filosofia da Caixa Preta: Ensaios para uma futura filosofia da fotografia (1985)" de Vilém Flusser, tendo como contraponto a obra "A Câmara Clara (1984)" de Roland Barthes, bem como a utilização dos princípios filosóficos clássicos como fundamentação e elucidação dos conceitos expostos.

"A Caixa Preta" é em suma uma coletânea de nove ensaios de Vilém Flusser, a referida obra possui subjetividade filosófica nos campos da semiótica, da estética e principalmente da fenomenologia, porém o seu estudo se torna complexo devido ao fato da ausência metodológica, comum no âmbito acadêmico, bem como a falta de referenciamento bibliográfico.

Para que se preserve seu caráter hipotético, o ensaio não citará trabalhos precedentes sobre temas visinhos, nem conterá bibliografia. Espera assim criar atmosfera de abertura para campo virgem. (FLUSSER, 1985, p.4)

Para que o presente trabalho possa contextualizar de forma eficiente e eficaz, o escopo deste artigo abordará apenas três dos ensaios de Flusser que perfazem a essência de uma possível filosofia da fotografia, a saber: "A imagem", "A imagem técnica" e "A fotografia".

A abordagem específica destes três ensaios justifica-se devido ao fato de Flusser, focar sua obra em um contexto geral a inter-relação do ato de fotografar com o aparelho utilizado para tal. Os capítulos acima citados adentram mais ao âmbito proposto neste artigo. Já os pressupostos de Barthes em "A Câmara Clara” têm como objetivo buscar os aspectos ônticos da Fotografia, em que o referente ${ }^{54}$ é priorizado, assim os aspectos do constructo de uma realidade na analise flusseriana são determinados pelo aparelho, porém em Barthes não assumem tal prioridade.

Apesar da aparente diferenciação e mesmo oposição ontológica das obras elencadas a Fotografia como imagem e representação é o fulcro e o viés a ser seguindo em ambas, pois os pontos de consonância podem ser maiores do que supostamente aqueles que lhes divergem.

Para chegar efetivamente a uma perspectiva ontológica da Fotografia é

\footnotetext{
${ }^{54}$ É definido por Barthes (1984, p. 20) como sendo espécie de pequeno simulacro emitido pelo objeto a ser fotografado.
} 
imprescindível a conceituação de vários elementos que a tornam uma realidade possível, porém tal tarefa não seria possível sem o necessário aprofundamento histórico da origem da Fotografia, mais precisamente da imagem como representação.

\section{DESENVOLVIMENTO}

Ao adentrar aos meandros ontológicos da fotografia primeiramente necessita-se aprofundar ainda mais na real significação da mesma, porém isso não seria possível sem efetuar uma criteriosa analise histórica e mesmo etimológica que a caracterizam. Contudo tal demanda por si só geraria um novo artigo, portanto tentar-se-á seguir um fluxo lógico com o mínimo necessário a um entendimento sucinto.

Segundo TAVARES, A.S.M. (2015), "Etimologicamente a palavra fotografia é

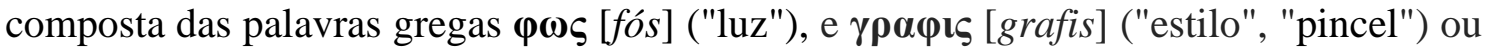

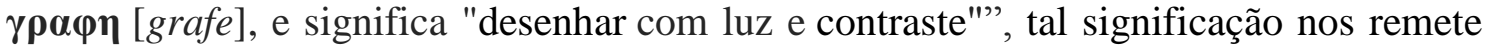
ao próprio sentido mecanicista da produção fotográfica, que é a técnica que por meios mecânicos, químicos ou digitais que fixa uma imagem sob uma camada sensível à exposição luminosa (luz) designada como seu suporte material.

Também podemos encontrar uma referência interessante da palavra fotografia na cultura japonesa, onde a mesma é denominada "shashin no dialeto kanji que etimologicamente é formada pelos ideogramas 写 [sha] (“tomar”) e 真 [shin] correspondendo a "verdade"," remontando assim a uma interpretação aproximada de "tomar a verdade", conforme DE ALMEIDA, A.P. (2012)

Dado os conceitos acima expostos é inevitável uma redução ontológica a dois elementos: luz e imagem. Ainda mais, seria possível propor que o que se busca aqui seria a exposição da imagem fotográfica a luz de sua verdade.

\section{A Imagem}

Imagens são superfícies que pretendes representar algo. $\mathrm{Na}$ maioria dos casos, algo que se encontra lá fora no espaço e no tempo. As imagens são, portanto, resultado do esforço de se abstrair duas das quatro dimensões espácio-temporais [...]. (FLUSSER, 1985, p.7)

Com estas palavras Vilém Flusser inicia o ensaio intitulado "A imagem", e mesmo que sob uma aparente superficialidade, as imagens tomam para si o status de 
representação, ainda que submetida e presa a Teoria da Relatividade ${ }^{\mathbf{5 5}}$ de Einstein.

Para Flusser as imagens ao serem criadas no plano sensível, são abstraídas da realidade material, ou seja, perdem duas características; a dimensão de profundidade e a dimensão de tempo, ficando assim condicionadas a bi-dimensionalidade.

Segue-se que a planificação das imagens a apenas duas das dimensões possíveis $^{\mathbf{5 6}}$, segundo a perspectiva flusseriana teriam uma realidade ontológica na capacidade humana da imaginação abstrativa, propondo de tal modo que a origem das imagens esta vinculada diretamente aos aspectos semióticos de criação e decodificação da mesma.

Consubstanciando assim a necessidade da interação do espectador e sua interferência direta, perpassasse a fotografia tal qual um scannig ${ }^{57}$ que captura algo original, gerando sua cópia, contudo Flusser acrescenta que tal processo retroage trazendo as dimensões abstraídas anteriormente no processo de criação e decodificação da imagem, a significação obtida por tal processo se apresentaria na dicotomia da intencionalidade do emissor - receptor.

E é na intencionalidade que é possível o inicio de uma inferência entre Flusser e Barthes, pois para o primeiro as "imagens têm o propósito de representar o mundo" (FLUSSER, 1985, p. 7), contudo o observador deixa de significar as imagens, passando a tomá-las como uma realidade a ser vivenciada.

Para que se possa referenciar "A Câmara Clara" de Roland Barthes (1984) como um contraponto, primeiro se faz necessário explaná-la, mesmo que em sua superficialidade. O fulcro da visão de Barthes esta em uma "divisão" tripartite de intencionalidade: fazer, suportar e olhar; sendo que as denominações de tais intencionalidades são dadas sob o viés do Spectator, que é aquele a quem se destina o Spectrum, no caso a Fotografia, já que nas suas próprias palavras: “Uma destas práticas me estava barrada e eu não devia procurar questioná-la: não sou fotógrafo, sequer amador [...]" (p. 20), ou seja, o fazer do Operator.

A intencionalidade da imagem na perspectiva barthesiana torna-se aprofundada em uma dimensionalidade onto-fenomenica quádrupla na Foto-retrato.

\footnotetext{
${ }^{55}$ Teoria da Relatividade é designada por três dimensões espaciais ((largura, profundidade e altura) e uma dimensão temporal (velocidade da luz)

${ }^{56}$ Pela atual Teoria das Cordas especula-se a existência de multi-dimensionalidade, 11 ao total.

57 Definição (FLUSSER, 1985, p. 5) em seu Glossário, como sendo o movimento de varredura que decifra uma situação.
} 


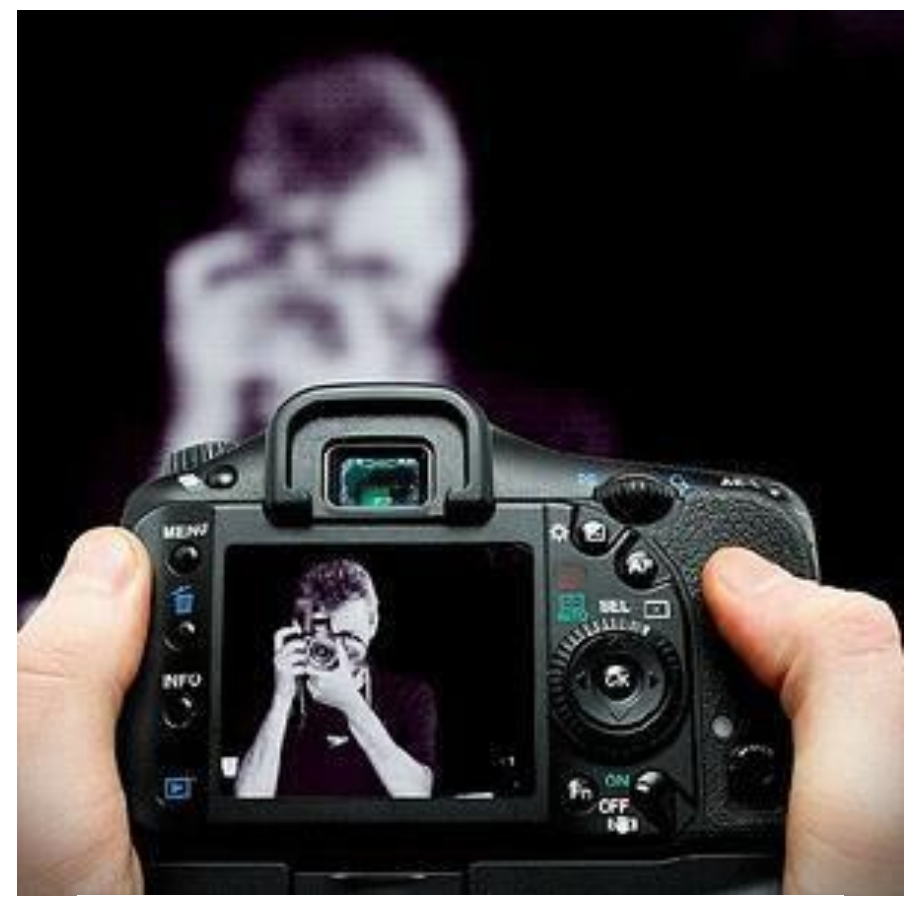

FIGURA 1 - Foto-montagem de autoria própria (2015)

Barthes ao se colocar como o referente assume um status espaço-temporal no presente em que ele se analisa bem como status do futuro em que como ele gostaria de ser analisado, podendo ser representado como o "Eu Spectator" em relação ao "Outro Spectator"; ainda há a analise do Fotógrafo como Operator que se utiliza do referente para criar o Spectrum que se destina novamente ao Spectator (Figura 1), tal qual imagética Ouroboros (Figura 2) em seu eterno retorno nietzschiano. 


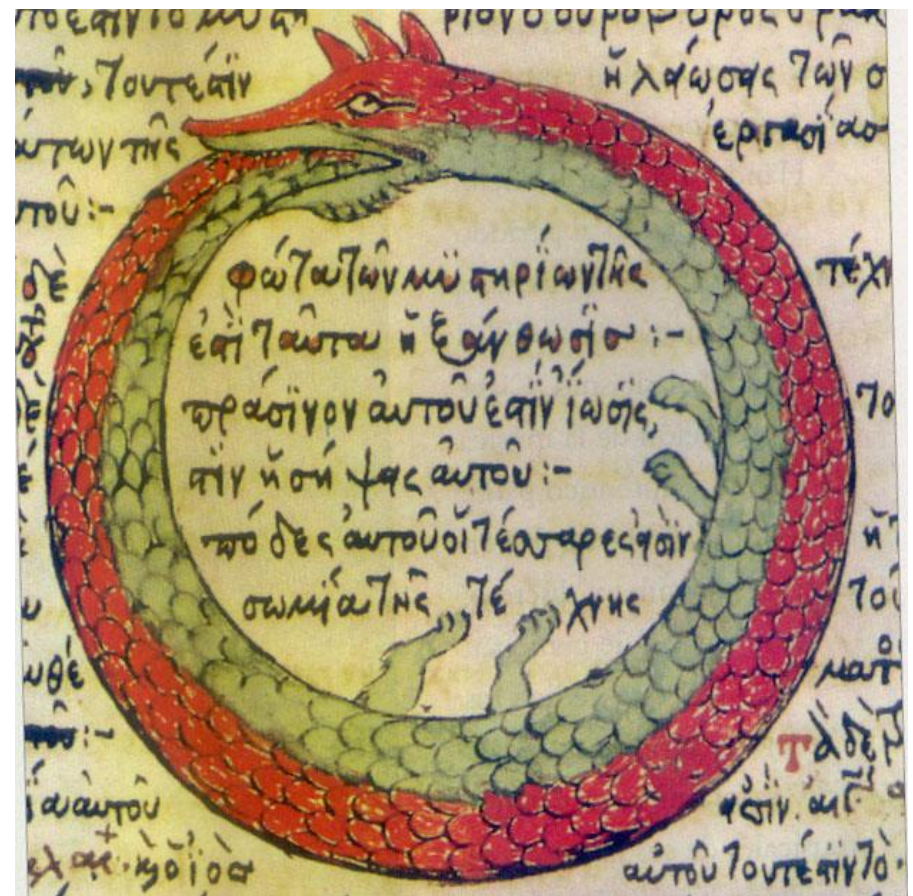

FIGURA 2 - Ouroboros - FONTE:

$<$ https://pt.wikipedia.org/wiki/Ouroboros\#/media/File:S erpiente_alquimica.jpg>. Acessado em: 02 out 2015

\section{A Imagem Técnica e A Fotografia}

No ensaio intitulado de "A imagem técnica" Flusser começa a descortinar o aspecto ontológico da imagem por meio da historicidade temporal. Para tanto distingue dois grandes períodos: pré-histórico e pós-histórico.

As imagens técnicas na perspectiva flusseriana são todas aquelas que são produzidas por meio de aparelhos que em si mesmos são os detentores das técnicas textualizadas pré-existentes, portanto seriam pós-históricas.

Já o aspecto ontológico encontra-se nas imagens pré-históricas denominadas como imagens tradicionais, sendo estas bi-dimensionais já que tiveram abstraídas as dimensões de espaço e tempo, conforme já citado anteriormente.

Ontologicamente, as imagens tracionais imaginam o mundo; as imagens técnicas imaginam textos que concebem imagens que imaginam o mundo. Essa posição as imagens técnicas é decisiva para seu deciframento. (FLUSSER, 1985, p.10) 
Novamente a imagética Ouroboros ronda e roda uma possível representação imaginativa da imagem. Historicamente a imagem foi o primeiro meio de representação conceitual antes do advento da escrita, tais representações das imagens tradicionais são abstracionismos fenomênicos de uma realidade visível e concreta, sendo criados não como símbolos, mas como signos que codificam conceitos numa semiose ${ }^{58}$. "Porém esta conceituação codificada naturalmente na imagem tradicional perde sua capacidade comunicativa quando dela é abstraída ainda uma dimensão secundária que é o texto, resultando na imagem técnica e esta somente recuperará seu status ontológico de imagem quando lhe for restituída a dimensão que lhe foi abstraída. Nesta mesma perspectiva a Fotografia é dada como essencialmente uma imagem técnica, onde sua representatividade ontológica nada mais é do que mimese do mundo real, visto que as mesmas seriam apenas abstrações simbólicas que codificam elementos textuais em imagens.” (FLUSSER, 1985, P.10)

A perspectiva flusseriana introduz um novo paradigma, o do reducionismo conceitual perpetrado pela imagem técnica que abstraí informações textuais complexas em uma simples e rasa forma de informação; a imagem. Esta concepção também adotada na "Câmara Clara", onde "a Fotografia é apenas uma contingência representativa, pois o texto pode apresentar ações que conduzem as informações às reflexões" (BARTHES, 1984, p. 49)

As codificações, ou ainda, as transcodificações de textos em imagens técnicas tem a sua origem em um binômio orgânico-mecanicista representada pelo operadoraparelho $^{59}$ que sintetiza a intencionalidade da imagem na pré-codificação (programa) do aparelho que induz a ação do operador. Mas tal perspectiva não estaria delegando uma intencionalidade a algo mecânico e inanimado, mesmo que em sua recôndita caixa-preta o programa tenha sido intencionalmente implantado pelo homem?

Diríamos que a Fotografia sempre traz consigo seu referente [...] (eu ainda não sabia que dessa teimosia do Referente em estar sempre presente, iria surgir a essência que eu buscava). Essa fatalidade (não há foto sem alguma coisa ou alguém) [...] (grifo nosso) (BARTHES, 1984, p. 15-16)

A concepção barthesiana do referente põe em foco a perspectiva fenomênica da

\footnotetext{
${ }^{58}$ Semiose a inter-relação processual entre o signo, designatum, interpretante e o interprete. (MORRIS, Charles. Fundamentos da teoria dos signos, 138, II, 3)

${ }^{59}$ O operador é o Operator de Barthes representado pelo Fotografo, já o aparelho é definido por Flusser (1985, p. 5) em seu Glossário como um brinquedo que simula um tipo de pensamento A junção operador-aparelho denota o enlace ontológico da imagem técnica flusseriana.
} 
Fotografia, desambiguando-o dos demais sistemas de representação, sendo que o referente é a concretude real e necessária para que seja possível a representação da imagem fotográfica.

O status empírico do referente também se diferencia de outras representações artísticas ou não, pelo fato que estas possam passar por simulacros imagéticos, tal quais as obras das artes-plásticas ou mesmo as literárias que em sem seu bojo possuem a capacidade de "criar" e mesmo "recriar" uma realidade inexistente por meio da imaginação; já a fotografia não pode furtar-se a coisa-em-si.

A Fotografia em relação ao Spectrum é referenciada pelo ad continuum ${ }^{60}$ espaçotemporal, porém de forma parcial, sendo um recorte referencial póstumo que na concepção barthesiana o seu intento "não é a Arte, nem a Comunicação, é a Referência, que é a ordem fundadora da Fotografia.” (BARTHES. 1985. p.115)

De tudo que foi até o presente momento depreendido é possível constatar uma imbricação onto-fenomenica que tem como causa recorrente a temporalidade da imagem, e como esta pode ferir os sentidos. Porém antes de aprofundar um pouco mais esta posição é necessário evocar alguns conceitos, a respeito dos binômios imagemimaginação, tempo-representação.

A investigação da imagem como tem sua historicidade iniciada como Platão em uma divisão ontológica das realidades sensíveis e supra-sensíveis da mímesis ${ }^{61}$, sendo que fenomenologia do sensível nada mais é do que um mero reflexo do mundo das ideias onde reside a verdade já Aristóteles procura na alma a essência imagética, tais proposições perduraram por muito tempo, influenciando até mesmo as obras de Flusser e Barthes.

Em sua obra "De Anima", Aristóteles propõe que as imagens são o produto da vontade sobre a imaginação e que esta seria o produto da interação das potências da alma (Aristóteles, 2006. p. 110), porém a imagem sendo compreendida sob a perspectiva de quem a percebe é reinterpretada no estoicismo em uma desambiguação onde poderia ser a forma livre, criada independentemente pelo pensamento onírico e também poderia ser a impressão que fere a alma, impressão esta que seria a própria alteridade anímica.

Com relação ao aspecto sensorial da imagem técnica Flusser a "localiza" na interioridade humana, pois sua representação não é a coisa concreta, mas sim a

\footnotetext{
${ }^{60}$ Quantidade ininterrupta ou contínua

${ }^{61}$ Termo platônico que significa imitação
} 
relatividade dos conceitos destas, independentemente da forma que estas impressionam a superfície da imagem.

Contrariamente as imagens tradicionais "tem uma simbologia em que o agente humano se interpõe entre as mesmas e a sua significação", esta interposição se dá na construção simbólica ansiada "em sua cabeça" e na transferência desta construção conceitual para a imagem propriamente dita por meio de suas mãos”. Aventa Flusser que uma possível decodificação das imagens tradicionais estaria sujeita ao descortinamento dos processos internos do agente humano. (FLUSSER, 1985, p. 10,11)

Ao reportarmo-nos a Aristóteles, este infere que a relação entre interioridade humana e o objeto é dada pelas faculdades sensíveis e intelectivas da alma em potência e não em ato, ou seja; o objeto concreto esta planificado na concretude e imprimido na alma sob forma.

\footnotetext{
[...] A ciência e a percepção sensorial dividem-se em conformidade com os seus objectos: por um lado, a ciência e a percepção sensorial em potência, em conformidade com os seus objectos em potência; por outro, a ciência e a percepção sensorial em acto, em conformidade com os seus objectos em acto. A faculdade perceptiva e a faculdade científica da alma são, em potência, os seus objectos, isto é: a última, o cientificamente cognoscível; a primeira, o sensível. É necessário, então, que tais faculdades sejam os próprios objectos ou as formas. Ora, os próprios objectos elas não podem ser, pois não é a pedra que existe na alma, mas sim a sua forma. A alma comporta-se, desta maneira, como a mão: a mão é um instrumento dos instrumentos, o entendimento é a forma das formas e o sentido é a forma dos sensíveis. [...] (ARISTÓTELES, De Anima VIII, 20, 25; 432a)
}

Interessante é que aqui se faz notar uma representativa semelhança com os pressupostos de Flusser, tanto no que se refere à forma como a imagem tradicional é materializada, quanto a sua perspectiva intrumentacionalista da imagem técnica, porém com relação à última compreende que o binômio operador-aparelho é enlace intencional que dá a imagem sua significação.

Aqui parece iniciar-se um distanciamento entre as concepções flusserianas e as barthesianas, porém tal distanciamento é superficial, dado que existe a intencionalidade e a despeito do fato de Flusser a situar no operador-aparelho, o operador é o sujeito ativo deste binômio e como tal é o único que possui a capacidade de intencionalidade; conforme Abbagnano (2007, p. 576) a intencionalidade "refere-se a qualquer ação ou ato humano em relação a um objeto diferente dele."

A intencionalidade da imagem técnica flusseriana é comunicada em suas próprias palavras como uma tarefa catalisadora, que intenta reunificar a ausência cultural da 
atualidade, ou em outras palavras re-significar a conceituação que foi abstraída durante o processo fotográfico e reintroduzi-los no cotidiano tal como são as imagens tradicionais. O mesmo ocorre na perspectiva barthesiana, contudo a intencionalidade já se encontra na própria fotografia sob o aspecto do punctum; que é "aquilo que escapa" da fotografia ferindo a alma. (BARTHES, 1984, p. 46)

O punctum, ou o ponto esta localizado no espaço e segundo Aristóteles em "De Anima (439 a)" é com o ponto que tem o princípio da linha. A Fotografia como se sabe é o continnum de pixels ${ }^{62}$ lineares a impressionar uma superfície sensível em um dado momento do tempo para representar a imagem.

Já na modernidade filosófica a imagem-imaginação passou pelo crivo do racionalismo; o $\log _{0 s} 63$ penso, existo de Descartes (1980) que instituiu "a imaginação como a contemplação imagética de algo concreto" (DESCARTES, 1996, p.22) e foi além com Kant onde os juízos sintéticos a priori ${ }^{64}$ inferem em uma 'imaginação empírica e uma sensorial produtiva, esta por sua vez distingui-se em imaginatio plastica que intui o espaço, a imaginatio associans que intui o tempo e imaginatio affinitas que unifica as representações de origem communis." (KANT, 2006, §31, p. 73).

Ao retomarmos a concepção de Flusser sobre como as imagens técnicas surgem em suas sucessivas abstrações dimensionais, verifica-se que as mesmas perante as faculdades imaginativas sensíveis de Kant poderiam ter novamente seu status ôntico restabelecido no quaternário Imaginatio-Spatium-Tempus-Repraesentatio ${ }^{65}$.

A perspectiva flusseriana pode ser retomada na imaginatio plastica segundo Kant (2006), com a intencionalidade imaginativa do operador-aparelho, e para que o aparelho possa sensibilizar uma superfície com a imagem é antes é necessário ter passado pelo construto imaginativo do operador, cuja representação intenta materializar, como o constructo imaginativo do operador é regido por processos racionais, tais processos seriam denominados em uma composição da imagem, tal qual se faz no processo de criação das artes plásticas como a pintura.

\footnotetext{
${ }^{62}$ Segundo o dicionário Michaelis (2008): Pixels (pl.) Pixel é a menor unidade ou ponto de um monitor de vídeo cuja cor ou brilho podem ser controlados; elemento de imagem.

${ }^{63}$ Logos é dado como a razão enquanto verdade (ABBAGNANO, 2007, p. 630)

${ }^{64}$ Juízo Sintético a priori segundo Kant (Crítica da Razão Pura) é aquele que é universalmente aceito e é apodítico, ou seja; acrescenta o conhecimento ao sujeito.

${ }^{65}$ Palavras latinas que significam respectivamente a imaginação, o espaço, o tempo e a representação, estando justapostas para identificar a interdependência das mesmas na consolidação do conceito ôntico da imagem. (ABBAGNANO, 2007, p. 348, 537, 853, 944)
} 
O jogo das forças, tanto na natureza inerte quanto na viva, tanto na alma quanto no corpo, repousa em decomposições e combinações de heterogêneos. Chegamos, sem dúvida, ao conhecimento deles pela experiência de seus efeitos; [...]. (KANT, §32, 172; 42, p. 76)

Já a imaginatio associans, recoloca a imagem técnica flusseriana na dimensionalidade temporal, visto que existem os processos racionais do operador, os mesmos acontecem em uma temporalidade e se tornam empiricamente efetivos quando é necessário efetuar diversas operações no aparelho para que se chegue a composição imaginada na Fotografia, desejada, há ainda o deslocamento temporal do être 66 (BARTHES, 1984, p. 115), em que a representação é aquilo consubstanciado daquilo que já foi o referente. Contudo como se expressa a representação?

A Fotografia em si já pode ser considerada como representação, mas se retornarmos aos conceitos flusserianos, veremos que todo o processo de conceituação de imagem técnica e seus reducionismos remontam à concepção kantiana de imaginatio affinitas só que inversamente, onde pode ser expressa analogamente a uma substância química homogênea como a água do mar (fotografia) que pode ser destilada por sucessivas abstrações dimensionais, para que resulte em seus componentes heterogêneos primários, água pura (imagem) e sal (representação imagética.).

A representação da Fotografia na visão de Flusser em um primeiro instante contrapõe-se racionalmente e logicamente aos princípios de necessidade e suficiência kantianos, uma vez para que a Fotografia possa existir em sua concretude há de existir o objeto a que ela se refere. Assim o princípio de representação da Fotografia esta focado em um binômio da existência espaço-temporal do objeto e da Idéia construtiva que se tem deste objeto.

\section{Considerações Finais}

Tal qual a perspectiva abstracionista de Flusser o presente artigo intentou reconstruir uma significação representativa da Fotografia, sendo que foi necessário desconstruir a imagem em seus elementos basilares, para que fosse possível ter algumas

\footnotetext{
${ }^{66}$ O verbo être foi utilizado na versão original "La Chambre Claire : Note sur la photographie" (BARTHES, 1980) sendo traduzido como "Isso-foi", contudo segundo a nota do tradutor a correspondência temporal pretendida neste artigo é melhor apreendida nas correspondências do verbo francês être, que conforme sua utilização na linguagem pode ser traduzido em português aos verbos infinitivos "ser", "estar" ou "existir, remetendo assim a dimensionalidade temporal, além da própria existência ontológica da fotografia. (N.T)
} 
perspectivas da Fotografia como representação.

Mediante ao escopo inicial é possível identificar a historicidade filosófica em relação às imagens, bem como o tratamento conceitual a elas dado, a noção de imagem é pré-histórica (FLUSSER, 1985), remontando aos rudimentos da linguagem pictórica, passando posteriormente do mythos ao lógos platônico e aristotélico.

A imagem remonta a antiguidade, contudo a Fotografia é contemporaneidade e modernidade, onde é que a fotografia começa a ter o seu status otológico desconstruído e mesmo desconstituído nas imagens técnicas flusseriana e reconstituídos na intencionalidade barthesiana.

É na aparente dicotomia da relação imagem e concretude realizada que surge a característica onto-fenomenica de representar o referente barthesiano em uma existência temporal, contudo a representação também esta imbuída da não - existência do mesmo.

Esta aparente dicotomia paradoxal do existir e não-existir começa a elucidar-se já na contemporaneidade, onde Kant (2006) reconstrói a imagem pela unificação da imaginação sensível produtiva, abalizando assim também as perspectivas de Barthes.

Porém não podemos perder de vista o viés da Fotografia, ainda que esta seja imagem e também seja representação, não deixa de ser uma imagem técnica e como tal ainda existem muitos aspectos ontológicos, tais como o da fotografia puramente digital, os quais não foram possíveis elencar neste artigo devido a sua profundidade e extensão e que por si só necessitariam de uma nova abordagem e quiçá de novas perspectivas onto-fenômenicas.

\section{Referências}

ABBAGNANO, Nicola. Dicionário de Filosofia. São Paulo: Martins Fontes, 2007.

ARISTÓTES. Sobre a Alma (De Anima). Obras Completas. Biblioteca de Autores Clássicos Lisboa: Imprensa Nacional-Casa da Moeda, 2010

BARTHES, Roland. A câmara clara. Rio de Janeiro: Nova Fronteira, 1984. DE ALMEIDA, Angela Prada. Portraits de Hiroshi Sugimoto: sobre realismo e retratos. Discursos Fotográficos, v. 8, n. 13, p. 101, 2012. Disponível em: http://www.uel.br/revistas/uel/index.php/discursosfotograficos/article/viewFile/10593/1 1292 . Acessado em: 30 set. 2015.

DESCARTES, René. Meditações. Col. Os Pensadores. São Paulo: Nova Cultural, 1996.

FLUSSER, Vilém. Filosofia da caixa preta: ensaios para uma futura filosofia da fotografia. São Paulo: Hucitec, 1985. 
KANT. Immanuel. Antropologia de um ponto de vista pragmático. São Paulo: Iluminuras, 2006.

Crítica da razão pura. São Paulo: Abril Cultural, 1980 (Os pensadores).

MICHAELIS. Dicionário escolar língua portuguesa. São Paulo: Melhoramentos, 2008.

MORRIS, Charles (1976). Fundamentos da teoria dos signos. Traduzido por Milton José Pinto. Revisão técnica por Nicolau Salum. Rio de Janeiro: Eldorado Tijuca; São Paulo: Editora da Universidade de São Paulo.

TAVARES, Amanda Savioli Marques. Fotografia e memória: instrumentos de documentação e criação. Leituras do Jornalismo, v. 2, n. 3, p. 142, 2015. Disponível em:http://www2.faac.unesp.br/ojs/index.php/leiturasdojornalismo/article/view/55.

Acessado em: 30 set. 2015.

\section{Nietzsche e a educação: Schopenhauer como exemplo de educador}

Luciana Vieira de Lima67

Resumo: Este artigo tem como propósito elaborar uma análise das críticas feitas por Nietzsche à educação e à cultura alemã de sua época, tendo, como fonte a terceira Consideração Extemporânea, intitulada: Schopenhauer Educador. Neste texto, Nietzsche faz um diagnóstico de que existiam três tendências no modelo educacional, que impossibilitavam o desenvolvimento de uma cultura autêntica: uma educação que visava apenas a instrução, a formação de homens dóceis e úteis, e, por último, a questão do eruditismo entre os professores; orientações que serviriam somente ao interesse do Estado, que buscava lucro e propriedade por intermédio de uma pseudocultura. Neste contexto, tanto a educação quanto a formação estavam subordinadas aos interesses do Estado. Contrapondo-se a esta concepção, Nietzsche vê a necessidade de que a educação e a formação tenham educadores que sejam modelos e exemplos, virtudes que Nietzsche encontrou em Schopenhauer, por ele não estar em consonância com os valores vigentes de sua época, pois só assim se pode pensar em uma cultura autêntica.

Palavras-chave: Nietzsche. Cultura. Educação. Schopehauer.

\section{Nietzsche and Education: Schopenhauer as an example of Educator}

Abstract: This article aims to elaborate an analysis of the criticisms made by Nietzsche to the education and the German culture of his time having as source the Untimely Meditations III: Schopenhauer as Educator. In this text Nietzsche makes a diagnosis that there were three tendencies in the educational model that prevented the development of an authentic culture: an education that aimed only at education, the formation of docile and useful men, and finally, the question of eruditism among teachers; Guidelines that would serve only the interest of the State, which sought profit and ownership through a pseudoculture. In this context, both education and training were subordinated to the interests of the State. Contrary to this view, Nietzsche sees the need for education and training to have educators who are models and examples, virtues that Nietzsche found in Schopenhauer because he is not in agreement with the current values of his time, because only in this way is it possible to think of an authentic culture.

Key Words: Nietzsche. Culture. Education. Schopehauer.

\footnotetext{
${ }^{67}$ Mestra (PUC PR). Doutoranda em Educação Filosófica (UFPR). Professora de Filosofia da Faced - Curitiba. Email:Iuna_lima@hotmail.com
} 